\title{
RECONHECIMENTO EM DEBATE: OS MODELOS DE HONNETH E FRASER EM SUA RELAÇÃO COMOLEGADO HABERMASIANO ${ }^{1}$
}

\author{
Ricardo Fabrino Mendonça
}

\begin{abstract}
RESUMO
O presente artigo busca delinear o debate travado por Axel Honneth e Nancy Fraser acerca da noção de reconhecimento, buscando compreender, especificamente, alguns dos aspectos que atravessam o projeto habermasiano de teoria crítica. Se a proposta de Honneth (de uma teoria da justiça calcada na noção de auto-realização) e a de Fraser (baseada no princípio da paridade de participação) parecem, à primeira vista, inconciliáveis, alguns elementos comuns podem ser encontrados quando se tem em mente o pano de fundo sobre o qual trabalham. Acreditamos que a possivel produção de um modelo de reconhecimento capaz de combinar proposições de Fraser e Honneth depende da explicitação de alguns pressupostos habermasianos que permanecem implícitos nas perspectivas aqui em análise. O presente artigo traça comparações e aproximações entre os três autores no que se refere, basicamente, a três aspectos: a importância das interações ordinárias, a dimensão material das lutas sociais e as relações entre direito e moral.
\end{abstract}

PALAVRAS-CHAVE: reconhecimento; teoria crítica; Honneth; Fraser; Habermas.

\section{INTRODUÇÃO}

A filosofia política vem assistindo a um acirrado debate em torno da noção de reconhecimento. Um crescente número de pesquisadores, de diversas áreas das ciências sociais, debruça-se sobre esse conceito desde que Charles Taylor (1994 [1992]) e Axel Honneth (2003a [1992]), cada um à sua maneira, retomaram trabalhos de Hegel para ressaltar a importância do reconhecimento intersubjetivo na auto-realização de sujeitos e na construção da justiça social. Seja para abordar os dilemas do multiculturalismo nas sociedades hodiernas, para refletir sobre as lutas voltadas para a construção da cidadania, para compreender os possíveis efeitos de políticas públicas que se querem inclusivas ou para diagnosticar padrões simbólicos desrespeitosos, o conceito de reconheci-

${ }^{1}$ O presente trabalho foi realizado com o apoio da Fapemig e do CNPq. Uma versão preliminar dele foi apresentada no Congresso Anual da Associação Brasileira de Pesquisadores em Comunicação e Política (Salvador, 2006), contando, para tanto, com financiamentos do PPGCOM-UFMG e da Capes (Procad). Gostaria de registrar meus agradecimentos a Leonardo Avritzer, Ângela Marques, Mariana Assis e aos pareceristas da Revista de Sociologia e Política pelas sugestões e comentários feitos no desenvolvimento deste artigo. mento mostra-se um instrumento heurístico bastante promissor $^{2}$.

Não há, contudo, homogeneidade em sua aplicação, o que se faz evidente pelas sucessivas críticas dirigidas por Nancy Fraser a Taylor e Honneth. Partindo de premissas filosóficas distintas das deles, Fraser propõe um paradigma de reconhecimento assentado na acepção weberiana de status e assinala a importância da redistribuição de recursos materiais, defendendo que, em diversos casos, desigualdades sociais não estão calcadas em padrões simbólicos de não-reconhecimento. Honneth, por sua vez, alega adotar uma visão mais ampla de reconhecimento, que não se res-

\footnotetext{
2 Cabe mencionar, aqui, a realização de uma série de pesquisas no Brasil que se pautam pela discussão teórica e empírica da idéia de reconhecimento. A título de exemplo, gostaríamos de citar os trabalhos de Souza $(2006,2003$, 2000a, 2000b), Mattos (2006, 2004), Feres Júnior (2006), Neves (2005), Bernardino (2002), Costa (2002), Lopes (2000), Marques (2003), Assis (2006), Cruz (2007), Mendonça e Maia (2006). Não é nosso intuito, todavia, discorrer neste artigo sobre os desdobramentos específicos da teoria do reconhecimento em pesquisas brasileiras. Salientamos, entretanto, a proficuidade do olhar proposto nos vários artigos que compõem a coletânea organizada por Jessé Souza (2006).
} 
tringiria à dimensão cultural da justiça, encampando os aspectos econômicos. Essa divergência teórica estende-se desde a segunda metade da década de 1990, culminando com a publicação conjunta de Redistribution or Recognition: a Political-Philosophical Exchange (FRASER \& HONNETH, 2003).

O objetivo do presente artigo é delinear os contornos de tal contenda filosófica, buscando apreender, especialmente, a influência de Jürgen Habermas tanto sobre as idéias de Honneth como sobre as de Fraser. O interesse por Habermas devese não apenas ao fato de ambos os autores aqui em questão travarem longos diálogos com ele ao longo de suas respectivas trajetórias acadêmicas ${ }^{3}$. Ele se justifica, principalmente, porque a atualização habermasiana da teoria crítica constitui o próprio pano de fundo a partir do qual Honneth e Fraser desenvolvem seu debate. O acento colocado por Habermas na construção intersubjetiva da política e da moral - bem como sua atenção aos processos dialógicos por meio dos quais os sujeitos configuram identidades, padrões culturais de interpretação e regras institucionalizadas de interação - atravessa a discussão Fraser $X$ Honneth, sendo que diferentes dimensões do projeto habermasiano são atualizadas por eles. Ao mesmo tempo, por outro lado, importantes aspectos desse mesmo projeto são, ainda que implicitamente, criticados no mencionado diálogo.

No intuito de observar tais questões, começaremos com uma apresentação da noção de reconhecimento, tal como desenvolvida por Taylor e Honneth. Em seguida, discutiremos algumas ressalvas levantadas ao conceito, introduzindo a visão de Nancy Fraser e analisando as implicações de seu modelo. Apontaremos, então, as linhas gerais da defesa de Honneth e abordaremos, por fim, alguns elementos do debate que são atravessados pelo pensamento de Habermas. Acreditamos que a possível produção de um modelo de reconhecimento capaz de combinar as proposições de Fraser às de Honneth depende da explicitação de alguns pressupostos habermasianos que permanecem

\footnotetext{
3 Basta lembrar que Honneth foi assistente de Habermas em Frankfurt, entre 1984 e 1990, e que Fraser tem importante reflexão acerca da noção de esfera pública, sendo que um de seus ensaios (FRASER, 1999) foi de suma relevância na revisão das posições que Habermas defendera em Mudança estrutural da esfera pública.
}

implícitos nas perspectivas aqui em questão.

\section{RECONHECIMENTO COMO GARANTIA DA AUTO-REALIZAÇÃO}

A teoria do reconhecimento, tal como inicialmente desenvolvida, pensa os conflitos sociais como buscas interativas pela consideração intersubjetiva de sujeitos e coletividades. Tendo como alicerce a filosofia hegeliana, autores como Charles Taylor (1994 [1992]) e Axel Honneth (2003a [1992]) ressaltam a construção relacional da identidade, frisando que os sujeitos lutam o tempo todo por reconhecimento mútuo. Segundo esses autores, somente dessa maneira eles podem se desenvolver de maneiras saudáveis e autônomas. A chave dessa perspectiva é, portanto, a compreensão da identidade como possibilidade de auto-realização.

Em seu ensaio seminal sobre o multiculturalismo, Charles Taylor (1994, p. 26) afirma que o reconhecimento não é uma questão de cortesia, mas uma necessidade humana. Isso porque pessoas e grupos podem sofrer danos reais se a sociedade os representa com imagens restritivas e depreciativas. Para Taylor $(1997 ; 1994)$, os sujeitos são construções dialógicas e é por meio das interações intersubjetivas (sejam elas agonísticas ou amistosas) que eles podem realizar a tarefa de serem verdadeiros com suas próprias originalidades. Em um mundo que construiu uma imagem individualizada de identidade, pautada pelo princípio de autonomia, "se eu não sou [verdadeiro comigo mesmo], eu perco o cerne da minha vida; eu perco o que o ser humano significa para mim" (TAYLOR, 1994, p. 30). Essa autonomia só pode ser construída em diálogos - em parte, externos e, em parte, internos - com os outros.

O projeto de Taylor está calcado em uma reconstrução histórico-filosófica dos alicerces valorativos que delineiam e estruturam a própria existência da sociedade. Como lembra Souza (2006), há hierarquias valorativas tácitas que perpassam as práticas cotidianas e instituições que se apresentam como neutras, tais como o mercado e o Estado. De acordo com o filósofo canadense, a própria configuração dos sujeitos, naturalizada no cotidiano, é guiada por princípios morais, amarrados no que ele denomina configurações. Uma "configuração incorpora um conjunto crucial de distinções qualitativas. Pensar, sentir, julgar no âmbito de tal configuração é funcionar com a sensação de que alguma ação ou modo de 
vida ou modo de sentir é incomparavelmente superior aos outros" (TAYLOR, 1997, p. 35). A identidade faz-se, portanto, inextricavelmente ligada a concepções de bem, que norteiam a vida dos sujeitos, garantindo-lhes o fundamento para juízos, intuições ou reações morais. "Taylor está interessado, antes de tudo, no componente avaliativo da constituição da identidade humana, na medida em que a auto-interpretação dos sujeitos passa a ser percebida como momento constitutivo para a construção desta" (SOUZA, 2000a, p. 99). São as configurações que permitem ao sujeito situarse na trama social e orientar-se.

Em uma espécie de arqueologia das concepções de bem, "Taylor pretende encontrar a autocompreensão dos atores na topografia moral da época e na cultura em que esses atores se inserem" (SOUZA, 2000b, p. 137). Ele assinala que, na contemporaneidade, "talvez o mais urgente e poderoso conjunto de exigências que reconhecemos como morais refira-se ao respeito à vida, à integridade, ao bem-estar e mesmo à prosperidade dos outros" (1997, p. 17). Assim, ele coloca a idéia de dignidade no cerne do pano de fundo moral que rege as sociedades ocidentais hodiernas, superestimando a capacidade destas de implementar uma universalização de direitos que naturalize o valor da igualdade (MATTOS, 2004, p. 157). De acordo com ele, na modernidade, houve um declínio da sociedade hierarquicamente predeterminada, o que levou a uma alteração da honra estamental em direção à dignidade geral. Por outro lado, o aludido desenvolvimento de uma acepção de self calcada nas noções de autenticidade e de interioridade suscita uma política da diferença. "Enquanto a política da dignidade universal lutava por formas de não-discriminação que eram bastante "cegas" aos jeitos em que os cidadãos se diferem, a política da diferença, freqüentemente, redefine a não-discriminação requerendo que façamos dessas distinções a base do tratamento diferencial" (TAYLOR, 1994, p. 39).

A proposta tayloriana de reconhecimento envolve esses dois tipos de política, estendendo a consciência da igualdade de valor humano para compreender a valorização daquilo que cada um fez a partir dessa igualdade. Para Taylor, por meio de lutas simbólicas, os sujeitos negociam identidades e buscam reconhecimento nos domínios íntimo e social. Ele aponta, ainda, que as lutas por reconhecimento têm-se feito cada vez mais explícitas, ultrapassando o foro interno, por via de pro- testos públicos. Protestos esses que não buscam a simples tolerância ou condescendência, mas o respeito e a valorização do diferente ${ }^{4}$. Para que isso ocorra, não deve haver uma generalizada valorização apriorística, mas uma profunda abertura a comparações, capazes de encetar fusões de horizontes, para usar os termos de Gadamer ${ }^{5}$. Não se trata, pois, de uma oposição de coletividades com seus próprios valores, mas da construção do respeito mútuo. Taylor não é, de modo algum, um defensor do relativismo (MATTOS, 2006).

As proposições de Axel Honneth (2003a) seguem um rumo semelhante às de Taylor, já que também ressaltam a existência de um contexto normativo que alicerça as representações e práticas sociais ${ }^{6}$. Honneth afirma que é por meio do reconhecimento intersubjetivo que os sujeitos podem garantir a plena realização de suas capacidades e uma auto-relação marcada pela integridade. Para o autor, os sujeitos são forjados em suas interações, sendo que eles só conseguirão formar uma auto-relação positiva caso se vejam reconhecidos por seus parceiros de interação.

4 Amy Gutmann explica a distinção entre tolerância e respeito à diferença, assinalando que "a tolerância se estende a uma gama mais ampla de perspectivas, na medida em que cessam as ameaças ou outros danos diretos e discerníveis aos indivíduos. O respeito é bem mais específico do que isso. Ainda que não precisemos concordar com uma posição para respeitá-la, precisamos entendê-la como refletindo um ponto de vista moral" (GUTMANN, 1994, p. 22).

5 De acordo com Taylor, a "fusão de horizontes opera por meio do desenvolvimento de novos vocabulários de comparação, através dos quais podemos articular esses contrastes" (1994, p. 67; sem grifos no original).

6 Importante destacar, entretanto, que Honneth é bem mais cauteloso do que Taylor ao abordar a universalização da dignidade no Ocidente. Além disso, a divisão analítica de três âmbitos do reconhecimento proposta por Honneth, da qual falaremos a seguir, oferece um quadro explicativo mais acurado que a divisão tayloriana entre as lutas íntimas e as públicas. Os domínios do amor, do direito e da estima, bem como a ligação destas últimas duas com a questão do trabalho e das desigualdades econômicas, permitem uma leitura mais complexa de conflitos sociais. Vale mencionar, por fim, que as entradas dos dois autores na teoria do reconhecimento são distintas: enquanto Taylor dá mais ênfase à "tarefa de fundamentação filosófica e histórico-filosófica da tese do reconhecimento social como vínculo mais básico e fundamental entre os indivíduos (MATTOS, 2006, p. 16), Honneth "procura sociologizar a teoria hegeliana original, destituindo-a de sua ganga metafísica por posturas abertas à investigação empírica" (ibidem). 
Buscando construir uma teoria social de caráter normativo, Honneth (2003a) parte do princípio de que o conflito é intrínseco tanto à formação da intersubjetividade como dos próprios sujeitos. Ele destaca que tal conflito não é conduzido apenas pela lógica da autoconservação dos indivíduos, como pensavam Maquiavel e Hobbes. Trata-se, sobretudo, de uma luta moral, visto que a organização da sociedade é pautada por obrigações intersubjetivas. Nesse sentido, o autor adota a premissa de Hegel, para quem os indivíduos se inserem em diversos embates por meio dos quais não apenas constroem uma imagem coerente de si mesmos, mas também possibilitam a instauração de um processo em que as relações éticas da sociedade seriam liberadas de unilateralizações e particularismos. Esses embates dar-se-iam, na visão de Hegel, nos âmbitos da família, do direito e da eticidade.

Honneth atualiza a idéia hegeliana por meio da psicologia social de George H. Mead. Assim como Hegel, o psicólogo norte-americano defende a gênese social da identidade e vê a evolução moral da sociedade na luta por reconhecimento. Mead (1993) aprofunda o olhar intersubjetivista, defendendo a existência de um diálogo interno (entre impulsos individuais e a cultura internalizada), e investiga a importância das normas morais nas relações humanas. De acordo com ele, nas interações sociais, ocorrem conflitos entre o "eu", a "cultura" e os "outros", por meio dos quais indivíduos e sociedade desenvolver-se-iam moralmente. Mead também embasa a idéia de reconhecimento em três tipos de relação: as primárias (guiadas pelo amor), as jurídicas (pautadas por leis) e a esfera do trabalho (na qual os indivíduos poderiam mostrar-se valiosos para a coletividade).

A partir da junção desses insights, Honneth sistematiza uma teoria do reconhecimento, afirmando que "são as lutas moralmente motivadas de grupos sociais, sua tentativa coletiva de estabelecer institucional e culturalmente formas ampliadas de reconhecimento recíproco, aquilo por meio do qual vem a se realizar a transformação normativamente gerida das sociedades" (HONNETH, 2003a, p. 156). Ele refina as categorias de relações apresentadas por Hegel e Mead, extraindo delas três princípios integradores: as $l i$ gações emotivas fortes, a adjudicação de direitos e a orientação por valores.
As primeiras se materializam por meio das relações de amor e seriam as mais fundamentais para a estruturação da personalidade dos sujeitos. Apoiando-se na psicanálise de Donald Winnicott, Honneth analisa as relações entre mãe e filho, indicando que elas passam por uma transformação que vai da fusão completa à dependência relati$v a$. Nessa dinâmica conflitiva, um aprende com o outro a se diferenciarem e verem-se como autônomos: ainda que dependentes, eles podem sobreviver sozinhos. Disso advém a possibilidade de uma autoconfiança. Para Honneth, em cada relação amorosa se atualiza o jogo dependência/ autonomia oriundo dessa fusão originária, dele dependendo a confiança básica do sujeito em si mesmo e no mundo.

As relações de direito, por sua vez, pautam-se pelos princípios morais universalistas construídos na modernidade. $O$ sistema jurídico deve expressar interesses universalizáveis de todos os membros da sociedade, não admitindo privilégios e gradações. Por meio do direito, os sujeitos reconhecem-se reciprocamente como seres humanos dotados de igualdade, que partilham as propriedades para a participação em uma formação discursiva da vontade. As relações jurídicas geram o auto-respeito: "consciência de poder se respeitar a si próprio, porque ele merece o respeito de todos os outros" (idem, p. 195). Honneth assinala que o que caracteriza essa igualdade humana é algo construído historicamente, sendo a modernidade marcada pela extensão dos atributos universais. Recorrendo às clássicas proposições de T. H. Marshall, o autor demonstra as lutas por reconhecimento travadas para a construção dos direitos civis, políticos e sociais, todos voltados para a configuração de cidadãos com igual valor.

A terceira, e última, dimensão do reconhecimento dá-se no domínio das relações de solidariedade, que propiciam algo além de um respeito universal. Honneth afirma que, "para poderem chegar a uma auto-relação infrangível, os sujeitos humanos precisam [...] além da experiência da dedicação afetiva e do reconhecimento jurídico, de uma estima social que lhes permita referir-se positivamente a suas propriedades e capacidades concretas" (idem, p. 198). Como explica Souza, o "espaço de positividade [dessa dimensão] é definido como aquele onde a honra no sentido tradicional não se transformou em dignidade (direito), 
mas antes na noção subjetivada de integridade" (2000b, p. 155). É no interior de uma comunidade de valores, com seus quadros partilhados de significação, que os sujeitos podem encontrar a valorização de suas idiossincrasias. E vários conflitos buscam, exatamente, a reconfiguração de tais quadros dada a revisibilidade destes: "Nas sociedades modernas, as relações de estima social estão sujeitas a uma luta permanente na qual os diversos grupos procuram elevar, com os meios da força simbólica e em referência às finalidades gerais, o valor das capacidades associadas à sua forma de vida" (HONNETH, 2003a, p. 207).

Aos três reinos do reconhecimento, Honneth associa, respectivamente, três formas de desrespeito: 1) aquelas que afetam a integridade corporal dos sujeitos e, assim, sua autoconfiança básica; 2) a denegação de direitos, que mina a possibilidade de auto-respeito, à medida que inflige ao sujeito o sentimento de não possuir o status de igualdade; e 3) a referência negativa ao valor de certos indivíduos e grupos, que afeta a auto-esti$m a$ dos sujeitos. Para Honneth, todas essas formas de desrespeito impedem a realização do indivíduo em sua integridade.

Mas se, por um lado, o rebaixamento e a humilhação ameaçam identidades, por outro, eles estão na própria base da constituição de lutas por reconhecimento. $\mathrm{O}$ desrespeito pode tornar-se impulso motivacional para lutas sociais, à medida que torna evidente que outros atores impedem a realização daquilo que se entende por bem viver. Esse é o ponto defendido por Honneth, quando, recorrendo a Dewey, afirma que os obstáculos que surgem ao longo das atividades dos sujeitos podem se converter em indignação e sentimentos que permitiriam um deslocamento da atenção dos atores para a própria ação, para o contexto em que ela ocorre e para as expectativas ali presentes. Disso poderiam advir impulsos para um conflito, desde que o ambiente político e cultural fosse propício para tanto. A idéia é que "toda reação emocional negativa que vai de par com a experiência de um desrespeito de pretensões de reconhecimento contém novamente em si a possibilidade de que a injustiça infligida ao sujeito se the revele em termos cognitivos e se torne o motivo da resistência política" (HONNETH, 2003a, p. 224).

O que Honneth defende, em suma, é que os conflitos intersubjetivos por reconhecimento, en- cetados por situações desrespeitosas vivenciadas cotidianamente, são fundamentais para o desenvolvimento moral da sociedade e dos indivíduos. Essa é a base de sua concepção formal de boa $v i d a$, a qual "tem de conter todos os pressupostos intersubjetivos que hoje precisam estar preenchidos para que os sujeitos se possam saber protegidos nas condições de sua auto-realização" (idem, p. 270). Tal eticidade formal - alicerçada no amor, no direito e na estima social - só poderia ser construída na interação social.

\section{CRÍTICAS E REVISÕES: O MODELO DE NANCY FRASER}

As idéias de Honneth e Taylor desencadearam um grande debate acerca da noção de reconhecimento, explicitando seu potencial para a compreensão de conflitos sociais e para uma renovação da teoria crítica. É importante perceber, contudo, que as formulações originais desses autores vêm sendo confrontadas e atualizadas desde meados dos anos 1990. Um dos aspectos mais controversos diz respeito a uma certa negligência teórica de Honneth e Taylor em relação às injustiças econômicas, cabendo citar, também, o temor de que as proposições deles reconduzam a visões de identidades autênticas essencializadas (TULLY, 2000; MARKELL, 2000; EMCKE, 2000; MCBRIDE, 2005).

Buscando construir um paradigma alternativo do reconhecimento, Nancy Fraser compartilha esse temor de que as proposições de Taylor e Honneth reconduzam a essencializações identitárias e sectarismos. No entanto, ela só sistematiza sua posição de forma clara e consistente depois de um longo percurso que a conduz de suas raízes neomarxistas ao campo da teoria crítica mais contemporânea.

Essa trajetória tem início em instigante ensaio, no qual Fraser (1997 [1995]) aponta que a justiça requer tanto a redistribuição como o reconhecimento. Ela chama a atenção para o campo da economia na construção de conflitos emancipatórios, defendendo a centralidade da esfera da produção na construção de uma sociedade mais justa. De maneira distinta de Taylor (1994), que não trata do problema, e de Honneth (2003a), que defende que a redistribuição faz parte do reconhecimento, Fraser aponta que essas lutas têm lógicas muito distintas, ainda que surjam quase sempre imbricadas. A redistribuição buscaria o fim do fator de diferenciação grupal, enquanto o reconhe- 
cimento estaria calcado naquilo que é particular a um grupo. Para Fraser (1997), isso gera uma esquizofrenia filosófica, já que as pessoas afetadas por injustiças materiais e culturais teriam que negar e afirmar sua especificidade ao mesmo tempo $^{7}$.

Buscando resolver esse dilema, Fraser dá continuidade a seu percurso em alguns ensaios (2000; 2001; 2003), nos quais se afasta, pouco a pouco, da justificativa marxista da economia, construindo um modelo que tem como categoria central a idéia de paridade de participação. Nesses textos, a autora critica, sistematicamente, o que chama de paradigma identitário do reconhecimento, cujos expoentes seriam Taylor e Honneth. Fraser (2000; 2003) julga que pensar o reconhecimento a partir da perspectiva de uma autenticidade identitária é um equívoco não apenas teórico, mas também político.

Ela acredita que tal viés geraria dificuldades para a observação empírica e conduziria à reificação de identidades e a uma incapacidade de discernir reivindicações justificáveis das não justificáveis. "Enfatizando a necessidade de elaborar e exibir uma identidade coletiva autêntica, autoafirmativa e autogerada, ele [o viés] coloca uma pressão moral nos indivíduos para que se conformem a uma dada cultura grupal" (FRASER, 2000, p. 112). Podem surgir, assim, formas repressivas de comunitarismo que reforçam dominações intragrupais, bem como sectarismos que conduzem ao separativismo social ${ }^{8}$.

\footnotetext{
7 Nesse ensaio, Fraser propõe que a solução seria adotar políticas transformativas, que buscam corrigir desigualdades a partir dos pressupostos que as embasam. A autora aponta que é somente por meio delas que se pode combinar redistribuição e reconhecimento sem gerar estratégias conflitantes. Em seus trabalhos mais recentes, todavia, Fraser $(2000 ; 2003)$ deixa de recomendar remédios específicos e propõe um olhar contextualizado.

8 Concordamos com Fraser no que se refere à afirmação de que a visão de identidades autênticas leva a sectarismos e a formas de dominação. Não percebemos, todavia, essa tendência nas obras de Taylor e Honneth. O primeiro não defende comunitarismos separativistas, como muito se apregoa, o que fica claro em sua proposta de uma fusão de horizontes. Honneth também tem um olhar intersubjetivista longe da reificação. Zurn (2003, p. 531) é bastante esclarecedor quando afirma que um modelo de reconhecimento baseado na noção de identidade não necessariamente conduz à intolerância, ao separativismo intergrupal e ao conformismo intragrupal.
}

Como alternativa, ela propõe um modelo de reconhecimento calcado na idéia weberiana de status. Nessa perspectiva, o não-reconhecimento não é explicado em termos de depreciação da identidade, mas como subordinação social: "o que requer reconhecimento não é a identidade específica do grupo, mas o status de seus membros individuais como parceiros por completo na interação social" (idem, p. 113). Assim, a análise do desrespeito adquire um objeto empiricamente palpável: padrões institucionalizados de desvalorização cultural, que constroem certas categorias de atores sociais como normativas e outras como inferiores. Estejam tais padrões instituídos em leis formais ou em sentidos informais, seu resultado é a configuração de atores que são menos do que membros efetivos da sociedade. Não há necessidade, pois, de investigar sentimentos de não-reconhecimento interiores aos sujeitos. Além disso, não é preciso se ater aos casos em que os próprios grupos percebem-se como desvalorizados.

Nota-se, que, sob esse viés, a luta por reconhecimento não procura a valorização de identidades, mas a superação da subordinação. Para tanto, faz-se necessário mudar valores e instituições reguladores de interações, o que varia em cada situação. $\mathrm{O}$ "modelo de status não está comprometido a priori com nenhum tipo de solução específica para o não reconhecimento" (ibidem). As soluções só podem ser elaboradas contextualmente.

Fraser $(2001 ; 2003)$ busca embasar, filosoficamente, esse projeto ao propor uma guinada da ética para a moral. De acordo com a autora, a primeira remonta ao conceito hegeliano de Sittlichkeit e diz respeito a valores historicamente configurados em horizontes específicos que não podem ser universalizáveis. A ética trata do bem viver. Já a moral está calcada no conceito kantiano de Moralität e se refere a questões de justiça, pautando-se pelo correto e não pelo bom. As normas da justiça seriam, para Fraser, universalmente vinculantes, não sendo tão contingentes como as da ética. Ao mover-se nessa direção, a autora nega a perspectiva defendida por Honneth e Taylor de que o reconhecimento seria uma questão de auto-relização. Assim, ela "liberta a força normativa de reivindicações de reconhecimento da dependência direta de um horizonte substantivo específico de valor" (2001, p. 25).

De acordo com ela, essa guinada teria quatro 
conseqüências imediatas. Em primeiro lugar, não se opta por uma concepção específica de bem em detrimento de outras: "o modelo de status é deontológico e não-sectário" (FRASER, 2003, p. 30). Em segundo lugar, o problema do desrespeito é situado em relações sociais e não em estruturas internas dos sujeitos, o que poderia culpabilizar as vítimas pela absorção da opressão ou levar à prática autoritária de policiamento de valores. Em terceiro lugar, ela "evita a visão de que todos têm igual direito à estima social" (idem, p. 32). Diferentemente de Honneth, ela diz que o que é preciso é que todos possam buscar estima.

A quarta conseqüência diz respeito à questão que motivou Fraser a construir todo o seu modelo: a guinada moral resolve a esquizofrenia filosófica causada por tentativas de atrelar as lógicas da redistribuição e do reconhecimento. Segundo Fraser, trata-se de duas dimensões da justiça, cuja integração não pode se dar pela redução de uma a outra. Uma vez que o objetivo é remover impedimentos à formação de relações simétricas, é possível pensar o imbricamento de ambas as lutas. A questão distributiva - que, curiosamente, ela atribui à tradição liberal em sua preocupação com as condições para a liberdade e não a Marx - alicerça as condições objetivas para a realização da paridade de participação. Os recursos materiais devem assegurar independência e voz aos participantes da interação social. Já a questão do reconhecimento estaria no cerne das condições intersubjetivas da paridade. "Padrões institucionalizados de valor cultural devem expressar igual respeito a todos os participantes e garantir oportunidades iguais para a obtenção da estima” (idem, p. 36) ${ }^{9}$.

9 Para se referir a obstáculos às condições objetivas e intersubjetivas da paridade, Fraser usa, respectivamente, os termos classe e status. Enquanto "classe é uma ordem de subordinação objetiva derivada de arranjos econômicos" (FRASER, 2003, p. 49), "status representa uma ordem de subordinação intersubjetiva derivada de padrões institucionalizados de valor cultural" (ibidem). Status e classe correspondem a dimensões analiticamente distintas: ainda que se imbriquem em jogos de influência recíproca, há, nas sociedades contemporâneas, um desacoplamento parcial dos mecanismos econômicos das estruturas de prestígio. Por isso, ela julga não serem adequadas nem as explicações economicistas (como as do marxismo ortodoxo), nem as culturalistas (como a que, na visão dela, Honneth defenderia), nem as desconstrucionistas (como as de Butler e Young). Fraser propõe um dualismo perspectivo em que qualquer prática pode ser pensada a partir das duas dimensões.
A chave da guinada de Fraser está, portanto, na idéia de paridade de participação. Este seria o padrão normativo que deveria reger tanto as lutas sociais como as análises de tais conflitos, e não a noção de auto-realização propagada por Taylor e Honneth. A visão desses autores permitiria, segundo ela, a valorização de identidades opressoras, por exemplo. No modelo de Fraser, só são justificáveis as reivindicações de reconhecimento que sejam moralmente vinculantes, fomentando a paridade de participação, sem gerar formas alternativas de subordinação. Como já dito, isso varia em cada situação, não sendo possível, por exemplo, predefinir se o reconhecimento deve se dirigir às especificidades de um grupo ou à consideração de uma humanidade comum. O importante é que as próprias pessoas afetadas participem, em processos dialógicos, da construção de soluções para superar quadros de subordinação.

Em sua proposta de uma teoria política, Fraser (2003) busca pensar os requisitos mínimos que tais soluções deveriam respeitar para atentar para as duas dimensões da justiça. Ela sugere que é preciso pensar nos "efeitos colaterais" dos "remédios" adotados, levando-se em conta que, muitas vezes, soluções de um problema desencadeiam outros. Ela defende, uma vez mais, que soluções transformativas (preocupadas com as raízes dos problemas) tendem a ser mais eficazes e aptas a conciliar a dimensão econômica à cultural. Mas como nem sempre essas soluções são exeqüíveis ou desejadas, pode-se pensar em reformas não reformistas: mudanças mais pontuais, capazes de gerar efeitos profundamente transformadores a longo prazo. Ela assinala, ainda, a importância de que decisões sejam revisáveis e do uso cruzado de soluções que, endereçadas a uma das dimensões da justiça, resolvam problemas da outra.

\section{RECONHECIMENTO COMO CATEGORIA AMPLIADA: A RESPOSTADE HONNETH}

Procurando contestar as críticas de Nancy Fraser, Honneth $(2001$; 2003b) defende a implausibilidade filosófica da distinção entre redistribuição e reconhecimento. Ele diz que Fraser está equivocada ao associar o reconhecimento à cultura. Nesse aspecto, ela seria a verdadeira reducionista, ao restringir a justiça à economia e à cultura. Para Honneth (2003b), a clivagem proposta por Fraser é arbitrária, desconsiderando múltiplas dimensões da justiça e negligenciando aspectos relevantes para o combate ao desrespei- 
to. Ele afirma que um paradigma do reconhecimento, suficientemente diferenciado, seria mais adequado para atualizar a teoria crítica, cunhando uma matriz atenta à construção intersubjetiva de sujeitos, da sociedade e da emancipação. E deixa claro que reconhecimento não é a simples valorização de grupos culturais.

Observa-se que Honneth frisa não negar a importância da distribuição de recursos materiais. Ele trata o reconhecimento como categoria ampla capaz de abrigar reivindicações de vários tipos. Assim, demandas por redistribuição material caberiam em sua proposta de duas maneiras: 1) nas implicações normativas de igualdade diante da lei, que promete tratamento equânime a todos os membros de uma comunidade política; e 2) na idéia de que cada membro de uma sociedade democrática deve ter a chance de ser socialmente estimado por suas realizações pessoais (HONNETH, 2001, p. 53). De acordo com Honneth, nem mesmo Marx considerava a distribuição material como um fim último. $\mathrm{O}$ importante é que ela garanta a instauração de formas de relação mais justas e respeitosas entre sujeitos. "Conflitos por distribuição [...] são sempre lutas simbólicas sobre a legitimidade do dispositivo sociocultural que determina o valor de atividades, atributos e contribuições" (idem, p. 54) ${ }^{10}$.

Nesse sentido, Honneth diz se afastar de Luhmann e Habermas, que pensariam o capitalismo como um sistema econômico não regido normativamente ${ }^{11}$. Ele afirma que valores definem como serão distribuídos os recursos, fazendo-se necessário reconstruir o conceito de lutas distributivas por meio do reavivamento de sua dimensão moral. Nesse sentido, "A postura de Fraser equivale a retirar da perspectiva teórica do reconhecimento precisamente seu principal mérito, que é haver contribuído para re-significar tudo aquilo que o alto capitalismo em sua atual fase de triunfalismo sem oposição tem tornado crescentemente naturalizado, muito especialmente na ordem econômica" (MATTOS, 2006, p. 157).

O grande problema do argumento de Honneth é que ele situa as lutas distributivas mais no âmbito

\footnotetext{
10 Para uma boa análise dessa perspectiva de Honneth e de seu enraizamento na teoria de Dewey, ver Zurn (2005).

11 Souza (2006) e Mattos (2006) também apontam que "Habermas não contempla uma perspectiva que permita uma análise dos aspectos simbólico e cultural das instituições, especialmente, Estado e mercado" (idem, p. 140).
}

do terceiro domínio do reconhecimento (o da comunidade de valores) do que no segundo (o das relações igualitárias). Ele diz que grupos devem lutar para que suas realizações sejam passíveis de valorização, construindo novos horizontes de valor. Mas, ao tratar a distribuição em termos de "realização" e "mérito", pode acabar conduzindo ao equívoco de justificar disparidades inadmissíveis ${ }^{12}$.

Outro aspecto marcante da resposta de Honneth (2003b) é sua acusação a Fraser por restringir os conflitos sociais a lutas organizadas e visíveis na esfera pública, negligenciando toda uma ampla gama de injustiças que afetam e depreciam identidades sem serem tematizadas. Para ele, Fraser generaliza a experiência dos conflitos norte-americanos, abordando apenas as lutas de atores que ultrapassaram a barreira da invisibilidade pública. Ela desconsideraria que formas de sofrimento e desrespeito profundamente enraizadas "também incluem aquelas que existem antes, e independentemente, da articulação política de movimentos sociais" (idem, p. 117).

Honneth critica, ainda, um certo procedimentalismo de Fraser e diz que a justiça não pode se ver inteiramente despida da ética. Para ele, "sem antecipar uma concepção de boa vida é impossível criticar quaisquer das injustiças contemporâneas" (idem, p. 114). Mas ele não propõe um simples relativismo em que as definições de uma comunidade decidiriam sobre o justo e o injusto. Com razão, ele afirma que Fraser interpretou equivocadamente suas proposições, deixando de observar sua preocupação como uma eticidade formal, a qual seria a medida para justificar (ou criticar) reivindicações sociais. Segundo ele, "uma concepção formal de ética contém as condições qualitativas para a auto-realização e difere da pluralidade de formas específicas de vida ao constituir as pré-condições gerais para a integridade pessoal de sujeitos" (HONNETH, 2001, p. 51) ${ }^{13}$

Ainda que essa definição de eticidade formal seja

12 Curiosamente, o próprio Honneth (2003a) negara a idéia de Mead de que o trabalho seria o âmbito privilegiado para a conquista da estima em processos de luta por reconhecimento.

13 No que concerne a esse aspecto, Cristopher Zurn (2003) corrobora a posição de Honneth, questionando a possibilidade de uma justiça totalmente despida da ética e destacando que o projeto de Honneth "tenta apresentar uma teoria normativa não-sectária que pode justificar reivindicações normativas que vinculem todas as pessoas" (idem, p. 528). 
apresentada de forma por demais abstrata, indicando poucos critérios para a avaliação empírica de lutas, seria injusto atribuir a Honneth um solipsismo sem parâmetros. Mesmo porque também a visão de paridade de participação de Fraser parece pouco delineada. Ambos buscam definir quais conflitos seriam justificáveis, mas, enquanto ela se pauta pelo bem da participação, ele prefere o bem da autorealização pessoal. Trata-se, no fundo, de concepções diferentes de justiça (HONNETH, 2003b, p. 176). Em Honneth, a justiça seria conseqüência do progresso moral da sociedade, avaliado em termos do reconhecimento de novas partes da personalidade ou da inclusão de outras pessoas nas relações de reconhecimento.

Cabe citar, por fim, duas últimas acusações que Honneth dirige a Fraser, a nosso ver, indevidamente. Ele afirma que: 1) ela não trata o problema das identidades agressivas; e 2) historiciza a mudança da economia para a cultura por meio de um enfoque similar ao de Taylor e também ao das chamadas teorias dos novos movimentos sociais. No que concerne à primeira crítica, Fraser (2003) busca, claramente, negar a legitimidade de identidades agressivas ao declarar que somente reivindicações que promovam a paridade de participação são justificáveis. No tocante à segunda, vale lembrar, como o faz Zurn (2005), que a autora procura, justamente, contestar a perspectiva historicista, evidenciando que praticamente todo conflito passa tanto pela dimensão cultural quanto pela econômica.

\section{TEORIA CRÍTICA EM FOCO: UM DEBATE QUEATRAVESSAAOBRAHABERMASIANA}

Apresentado o debate entre Honneth e Fraser, interessa-nos, agora, observar sua relação com a obra de Jürgen Habermas. Isso porque ambas as propostas de reconhecimento procuram atualizar a teoria crítica, entrando em diálogo com as trilhas abertas pelo projeto habermasiano a partir do referencial frankfurtiano. Cabe lembrar que a proposta inicial dos pensadores do Institut für Sozialforschung era construir uma teoria que "não se limita a descrever o funcionamento da sociedade, mas pretende compreendê-la à luz de uma emancipação ao mesmo tempo possível e bloqueada pela lógica própria da organização social vigente" (NOBRE, 2003, p. 9). A partir da discussão dos processos de racionalização engendrados pela modernidade, os autores da primeira geração de Frankfurt defendem que o mundo do trabalho, da técnica e da produção conduziram a uma for- ma de racionalidade única (a instrumental) que levaria à naturalização da dominação e à supressão do esclarecimento (cf. ADORNO \& HORKHEIMER, 1985). A transformação social adviria, de acordo com esse viés, de alterações no próprio mundo da produção e da técnica.

A atualização habermasiana da teoria crítica nega tanto esse diagnóstico como o caminho para sua superação. Habermas (1980a; 1983; 1987) defende que, por maior que seja a ubiqüidade da racionalidade instrumental, ela não esgota o projeto moderno de racionalização. Em diálogo com Marcuse, ele alega que a teoria crítica não pode operar apenas no interior do paradigma da pro$d u c ̧ a ̃ o$, preocupado com as relações que conduzem à transformação da natureza. Habermas (1980a) afirma a importância de se olhar para a linguagem: é na racionalidade comunicativa voltada para o entendimento mútuo - que os sujeitos atualizam e reconfiguram o mundo (em suas dimensões objetiva, social e subjetiva), residindo aí o cerne do potencial emancipatório do projeto da modernidade. O próprio questionamento da lógica do mundo da produção depende, assim, de um tipo de ação distinto das ações instrumentais e estratégicas que visam ao sucesso e operam nos quadros dos modelos vigentes. Diferentemente dos primeiros frankfurtianos, a normatividade buscada por Habermas é construída linguageiramente, por meio da discussão pública sem restrições ${ }^{14}$.

Na perspectiva de Habermas (1987; 1997), a sociedade deve ser compreendida a partir de uma divisão analítica entre sistemas funcionais e o mundo da vida. Enquanto aqueles são regidos por códigos e procedimentos específicos cuja validade só pode ser avaliada no interior de cada sistema, o mundo da vida compõe a trama de significados tácitos e tidos como certos, atualizada no uso comunicativo da linguagem ${ }^{15}$. O mundo da

\footnotetext{
14 Não se deseja sugerir, aqui, que Habermas vê como negativas as ações estratégicas e as instrumentais, nem que ele negue a importância do trabalho e do mundo da produção na emancipação do homem. $\mathrm{O}$ que ressaltamos é a importância dos acordos normativos comunicativamente construídos até para que as estruturas do mercado possam ser repensadas e alteradas.

15 Amplamente explorado pela fenomenologia, sobretudo por Husserl e Schütz, o conceito de mundo da vida (Lebenswelt) refere-se ao contexto preliminar que marca a experiência cotidiana do mundo. "O que o caracteriza, em primeiro lugar, é o modo de uma certeza imediata" (HABERMAS, 1990, p. 92)
} 
vida serve de pano de fundo às ações comunicativas: interações simbolicamente mediadas que visam ao entendimento mútuo.

Nesse tipo de interação, os interlocutores "não utilizam a linguagem 'perlocutoriamente', isto é, visando instigar outros sujeitos para um comportamento desejado, mas 'ilocutoriamente', isto é, com vistas ao estabelecimento não-coercitivo de relações intersubjetivas" (HABERMAS, 1980b, p. 103). Isso se dá por meio do levantamento recíproco de pretensões de validade criticáveis ${ }^{16}$, diante das quais os sujeitos assumem posicionamentos em termos de sim/não. Dessa forma, eles podem alterar ou sustentar fragmentos dessa rede simbólica que os precede, já que o poder-dizer-não instaura uma fratura deontológica (HABERMAS, 1997, v. 2, p. 53). As normas sociais se mantêm ou são questionadas na troca intersubjetiva.

É justamente no uso da racionalidade comunicativa que Habermas deposita suas esperanças ${ }^{17}$. Como atesta Honneth, "Habermas deu uma guinada na tradição da teoria social crítica, na medida em que transferiu o potencial emancipatório, transcendente, da prática do trabalho para o mo-

16 Habermas $(1983 ; 1987 ; 1990)$ propõe que o uso público da linguagem visando ao entendimento mútuo mobiliza uma forma de racionalidade, que dialoga com as dimensões objetiva, social e subjetiva do mundo. Recorrendo às idéias de Bühler e Austin, ele lembra que proferimentos usados comunicativamente expressam intenções de um falante, representam estados de coisas e estabelecem relações com um destinatário (HABERMAS, 1990, p. 78). Nessa tríplice relação, os enunciados envolvem, além de uma sempre presente pretensão de compreensibilidade, pretensões de verdade, de correção e de veracidade. Qualquer uma dessas pretensões é passível de questionamento.

17 Como apontado por um dos pareceristas anônimos da Revista de Sociologia e Política, reconhecemos que em The Theory of Communicative Action, o autor adota uma perspectiva bastante pessimista ao tratar a questão da colonização do mundo da vida. Para Habermas (1987, p. 283) “o padrão capitalista de modernização é marcado por uma deformação, uma reificação das estruturas simbólicas do mundo da vida sob os imperativos de subsistemas diferenciados via dinheiro e poder e tornados auto-suficientes". Não se pode, todavia, negligenciar o potencial emancipatório depositado por Habermas na ação comunicativa nem defender que seu diagnóstico é o de uma submissão completa da racionalidade comunicativa à estratégica. Seu olhar ambivalente fica claro nos desdobramentos posteriores de sua teoria, sobretudo na conformação do modelo deliberacionista de democracia. delo de ação da interação lingüisticamente mediada" (HONNETH, 2003c, p. 246). De acordo com Habermas, os sujeitos podem, reflexiva e dialogicamente, reconfigurar aspectos do mundo, das relações sociais e das próprias identidades ao se posicionarem diante de pretensões de validade reciprocamente levantadas. É na ação comunicativa - na livre troca de argumentos voltados para o entendimento - que se atualizam e se alteram sentidos sobre o mundo em suas múltiplas dimensões, podendo a realidade ser reconstruída de forma não opressora.

Importante destacar que, no viés habermasiano, a dominação e a subordinação não são meros reflexos da lógica instrumental-estratégica. Esta não seria, por si só, negativa, sendo mesmo necessária no campo do trabalho. O problema é quando as formas estratégicas de ação começam a interferir em âmbitos que devem ser regidos pelo medium da linguagem, tecnificandoos. Nesses casos, dar-se-iam os processos de colonização do mundo da vida: "mecanismos sistêmicos suprimem formas de integração social, mesmo nas áreas em que a coordenação dependente do consenso não pode ser substituída, ou seja, onde a reprodução simbólica do mundo da vida está em questão" (HABERMAS, 1987, p. 196). Para impedi-la, Habermas aposta na dimensão moral da política, proveniente da troca comunicativa intersubjetiva. Honneth (2003c, p. 242) salienta esse aspecto quando coloca que, na obra de Habermas, "o potencial moral da comunicação é o motor do progresso social, indicando, ao mesmo tempo, sua direção".

A inscrição dos teóricos do reconhecimento no campo da teoria crítica também se apóia sobre a dimensão moral e intersubjetiva da política ${ }^{18}$. Refletindo sobre a questão da dominação e da emancipação nas sociedades hodiernas, eles buscam diagnosticar as mazelas contemporâneas -

18 É interessante perceber, aqui, que nos referimos à dimensão moral da política e não do sistema político administrativo, já que Habermas entende este último como um sistema social que usa a racionalidade estratégica orientada pelo medium do poder. Pensada sob uma acepção alargada, como veremos a seguir, a política não se restringe às instituições administrativas do Estado, configurando-se como uma prática mais ampla, como já defendiam Aristóteles e Arendt. É essa percepção que leva Habermas a formular seu modelo de política deliberativa calcado na idéia de circulação de poder. 
traduzidas em termos de desrespeito (Honneth) ou de injustiça (Fraser) - e propõem uma gramática moral para a superação delas. Tal como Habermas, e antes dele Hegel, Honneth e Fraser percebem que a política não se restringe a uma luta de interesses (à ação estratégica) ${ }^{19}$. Há horizontes normativos, coletiva e simbolicamente atualizados, sobre os quais os sujeitos se apóiam. Tais horizontes estão na base de reivindicações levantadas contra formas de opressão ou desrespeito, o que explicita a permanente tensão entre a facticidade da vida social e sua normatividade de que fala Habermas (1997).

\section{V.1. A importância das interações ordinárias}

A força da noção de intersubjetividade, presente nos três autores aqui em tela, acaba por conduzi-los a uma compreensão ampliada da política, chamando a atenção para a participação dos cidadãos em suas vidas cotidianas. Diferentemente da tradição que remonta a Weber e Luhmann, que vêem a política como um campo especializado e autopoiético (cf. HABERMAS, 1997, v. 2), Habermas, Honneth e Fraser enfocam a práxis ordinária dos cidadãos, evidenciando sua centralidade para a política. Eles buscam compreender os processos de produção de decisões coletivas na perspectiva dos participantes e não apenas na do observador.

Habermas $(1992 ; 1997)$ fá-lo ressaltando o potencial do uso corriqueiro da linguagem natural por cidadãos comuns. Segundo ele, os proferimentos desses sujeitos ganham concretude e visibilidade em uma multiplicidade de arenas intersubjetivas, cuja trama configura uma esfera pública, capaz não apenas de reconfigurar entendimentos coletivos e padrões culturais, mas também de gerar um poder comunicativo que pode influenciar as instâncias formais de decisão política $^{20}$. Isso porque, "em sociedades complexas,

\footnotetext{
19 Honneth reconhece, explicitamente, que Habermas foi um dos poucos teóricos a colocar as expectativas normativas no cerne da política (HONNETH, 2003b, p. 128-9). Vale ressaltar que Habermas parte da "premissa, segundo a qual o modo de operar de um sistema político, constituído pelo Estado de Direito, não pode ser descrito adequadamente, nem mesmo em nível empírico, quando não se leva em conta a dimensão de validade do direito e a força legitimadora da gênese democrática do direito" (HABERMAS, 1997, v. 2, p. 9).

20 Habermas (1997, v. 2) desenvolve essa perspectiva a partir do modelo de circulação de poder de B. Peters. A
}

a esfera pública forma uma estrutura intermediária que faz a mediação entre o sistema político, de um lado, e os setores privados do mundo da vida e sistemas de ação especializados em termos de funções, de outro lado" (HABERMAS, 1997, v. 2, p. 107).

A noção de esfera pública é a base da proposta habermasiana de uma política deliberativa que "obtém sua força legitimadora da estrutura discursiva de uma formação da opinião e da vontade, a qual preenche sua função social e integradora graças à expectativa de uma qualidade racional de seus resultados" (idem, p. 28) 21 . Recorrendo a Joshua Cohen, Habermas (idem) afirma que as deliberações estão baseadas em trocas públicas de argumentos por todos os interessados por um determinado assunto. Os participantes seriam livres de coerções externas e internas, considerando que as tomadas de posição são regidas pelo princípio do melhor argumento. Passíveis de tratar quaisquer questões tematizadas como publicamente relevantes e mantendo-se sempre abertas a revisões, as deliberações buscam acordos racionalmente motivados, dependendo das mudanças de preferências dos sujeitos participantes. Como se vê, trata-se de um jeito de pensar a política de forma inclusiva e participativa.

Nancy Fraser $(2000 ; 2003)$ parece bastante ligada à proposta de Habermas, quando chama a atenção para o fato de que políticas eficazes, capazes de combinar distribuição econômica e reconhecimento cultural, não podem ser cunhadas sem a participação das pessoas em processos dialógicos. Nesse ponto, ela mobiliza o princípio

idéia é a de que o sistema político tem um núcleo adminis trativo responsável pelas tomadas de decisão e periferias com distintos poderes de influência. Nesse modelo, os cidadãos comuns podem iniciar fluxos comunicativos capazes de pressionar os centros do sistema no sentido da transformação. Tais fluxos passam por sucessivas comportas, defendendo-se publicamente e formando um poder comunicativo, capaz de forçar modos extraordinários de solução de problemas.

21 De acordo com Habermas, uma das razões pelas quais seu projeto difere, de um lado, das visões liberais e, de outro, das republicanas, está na função atribuída à formação democrática da vontade. Ele afirma que, para os liberais, essa formação teria o papel de legitimação do poder, enquanto que, para os republicanos, ela constituiria a própria sociedade. "Racionalização significa mais do que simples legitimação, porém menos do que a constituição do poder" (HABERMAS, 1997, v. 2, p. 23). 
$D$ habermasiano, segundo o qual "são válidas as normas de ação às quais todos os possíveis atingidos poderiam dar o seu assentimento, na qualidade de participantes de discursos racionais" (HABERMAS, 1997, v. 1, p. 142)22. É na prática argumentativa, no give-and-take de razões, que os sujeitos pesam escolhas, avaliam propostas e constroem soluções coletivas para problemas complexos. Somente com a participação deles - que deve ser paritária, vale frisar -, as soluções direcionadas à subordinação poderiam conciliar a dimensão econômica da justiça à cultural, de forma a amenizar "efeitos colaterais".

A proposta de Fraser caminha no sentido de um ciclo virtuoso da participação: por meio dela, os sujeitos construiriam quadros interacionais mais propícios à inclusão de todos como pares por inteiro em interações sociais. Uma vez mais, apontamos a forte relação dessa idéia com a visão de Habermas, para quem "a esfera pública política tem que se estabilizar, num certo sentido, por si mesma" (HABERMAS, 1997, v. 2, p. 102). É no próprio ato da participação comunicativa que esta se estabelece e se aprimora. Em Fraser, a participação paritária, moralmente construída e justificada, é o eixo que deveria guiar a teoria crítica.

Por fim, ainda no que concerne à relevância das práticas ordinárias, nota-se que Honneth (2003a; 2003b) também destaca o papel das lutas intersubjetivas cotidianamente travadas. Ele aponta que, por meio de relações afetivas, jurídicas e sociais, o sujeito constrói-se interacionalmente, e esse processo de construção é profundamente político. É por meio das lutas (individuais ou coletivas) para fazerem-se reconhecidos - como pessoas carentes, como seres humanos dotados de igualdade e como indivíduos passíveis de estima - que os sujeitos promovem o progresso moral da sociedade, construindo padrões de interação mais justos e favoráveis à auto-realização. Ainda que Honneth não defenda a troca argumentativa como forma privilegiada de transformação política, o

\footnotetext{
22 Embora Honneth afirme que, nesse aspecto, a visão de Fraser descende diretamente da obra habermasiana, ele julga tratar-se de uma apropriação pouco adequada. Para ele, Fraser sobrecarrega um conceito que se pretendia puramente procedimental: "A formação democrática da vontade que Habermas tem em mente com seu conceito de 'soberania popular' engloba muito menos do que as intuições normativas de Fraser" (HONNETH, 2003b, p. 178).
}

foco no potencial emancipatório das relações cotidianas e a visão de que a intersubjetividade é constitutiva dos sujeitos, da cultura e das regras sociais são reconhecidas heranças do projeto de Habermas.

Honneth apóia seu projeto nas interações do mundo da vida, enfocando, especificamente, um de seus componentes: a estrutura pessoal ${ }^{23}$. O próprio Habermas já defendia o potencial da $a c ̧ a ̃ o$ comunicativa no desenvolvimento moral da sociedade ao discorrer sobre seu impacto na formação identitária. Para ele, a "racionalização das normas sociais seria caracterizada precisamente por um grau reduzido de regressividade (o que no plano da estrutura da personalidade, deveria fazer crescer a média de tolerância, face ao conflito entre os papéis)" (HABERMAS, 1980a, p. 331). Mas Habermas não coloca a formação de sujeitos dotados de uma auto-realização positiva no centro de seu projeto. O objetivo da justiça, em sua visão, é mais amplo, sendo que há critérios morais que não passam pela construção da autoconfiança, do auto-respeito e da auto-estima.

\section{V.2. A dimensão material das lutas sociais}

Outro aspecto a ser discutido em relação aos três projetos de teoria crítica aqui em análise diz respeito à forma como concebem a questão redistributiva. Em nossa compreensão, todos eles reconhecem a relevância dela, embora lhe atribuam diferentes acentos. Cabe ressaltar, antes de tudo, que os três realizam um progressivo afastamento do legado marxista. Habermas, Honneth e Fraser demonstram-se críticos da dualidade infra $X$ superestrutura, depositando um peso bem maior na cultura e nas interações linguageiras do que Marx, mesmo em uma leitura pouco ortodoxa, poderia admitir. Observa-se, também, um distanciamento de categorias caras ao marxismo como ideologia e luta de classes. Ainda que Fraser (2003) adote o termo classe para se referir a formas de dominação econômica, ela não defende tratar-se de uma identidade coletiva coesa, voltada para a tomada e supressão do Estado. Os três autores indicam o papel político (e emancipatório)

23 Habermas $(1987$; 1990) assinala que o lebenswelt é composto de três dimensões que se imbricam: a) cultura (estoque de conhecimento que abastece as interpretações dos sujeitos); b) sociedade (ordens legitimadas que regulam afiliações) e c) estrutura pessoal (biografia e experiência do indivíduo). 
dos indivíduos em suas relações sociais, e não de uma classe ou coletividade específica. Honneth (2003b, p. 124) explicita esse aspecto ao declarar que um dos equívocos de Marx foi pensar o proletariado como o representante dos descontentes. Habermas também diz não ser possível localizar as injustiças sociais em uma única classe.

Na obra de Habermas, a questão redistributiva aparece como que no pano de fundo. Ele reconhece a importância dos bens materiais e de formas mais equânimes de distribuição para que os sujeitos possam participar da vida social e dos processos de decisão política. Ele afirma, por exemplo, que, em Estados democráticos, o sistema dos direitos não pode fechar os olhos para as condições de vida desiguais (HABERMAS, 2002, p. 243). Mas, como já dito, não é no reino da economia e dos recursos materiais que ele deposita suas esperanças emancipatórias. Um dos pontos centrais do projeto habermasiano é demonstrar, em debate com seus antecessores frankfurtianos, que a transformação da sociedade deve ser guiada pela ação comunicativa voltada para o entendimento. É por meio do uso racional e intersubjetivo da linguagem que os sujeitos podem buscar construir outros mundos possíveis, sedimentando novos padrões culturais, regras sociais e práticas de socialização no mundo $d a$ vida e influenciando decisões formais.

Honneth acompanha Habermas de perto nessa empreitada, defendendo a tese de que o mundo transforma-se (e evolui moralmente) por meio das lutas intersubjetivas por reconhecimento mútuo. É no mundo da vida que se naturalizam e se questionam enraizados padrões de desrespeito, sendo que os indivíduos buscam, diariamente, fazer-se reconhecidos para se auto-realizarem. A questão da distribuição é pensada por Honneth (2003b) a partir de um modelo diferenciado de reconhecimento. Como já abordado, ele alega que os sujeitos lutam por bens materiais tanto para se verem considerados seres humanos de igual valor, como para verem reconhecidos seus méritos e realizações distintivos. É a partir da lógica do reconhecimento, e não simplesmente visando ao aumento de bens materiais, que os sujeitos aspirariam a práticas redistributivas.

Fraser, por sua vez, representa como que uma ruptura nessa perspectiva centrada no mundo da vida. Ela redirige a atenção da teoria crítica para o campo da economia, argumentando que nem tudo pode ser resolvido no plano da construção de significações. Se a comunicação intersubjetiva é fundamental para a alteração de regras e para a construção de padrões paritários de interação, sem uma igualdade de recursos materiais não há condições objetivas para que isso ocorra. Nesse sentido, Fraser busca marcar sua entrada no campo da teoria crítica, por uma reconsideração de aspectos que estavam em suas origens, mas que foram pouco a pouco saindo de foco.

\section{V.3. Direito e moral: justiça sem ética?}

Um terceiro aspecto a ser pontuado no cruzamento das obras de Honneth e Fraser com o legado habermasiano refere-se à noção de direito. Ambos colocam a idéia de direitos no cerne de suas propostas para uma teoria da justiça, entendendo que eles não são simplesmente o reflexo de interesses de grupos dominantes, mas construções intersubjetivas dotadas de uma carga moral. Nesse aspecto, eles dão seqüência à trilha desenvolvida por Habermas, para quem "o Direito é um medium que possibilita o translado das estruturas de reconhecimento recíproco - que reconhecemos nas interações simples e nas relações de solidariedade natural - para os complexos e cada vez mais anônimos domínios de ação de uma sociedade diferenciada funcionalmente, onde aquelas estruturas simples assumem uma forma abstrata, porém impositiva" (HABERMAS, 1997, v. 2, p. 46).

Ainda de acordo com Habermas, em condições pós-metafísicas, "as ordens jurídicas só podem ser construídas e desenvolvidas à luz de princípios justificados racionalmente, portanto universalistas" (HABERMAS, 1997, v. 1, p. 101). Tanto Honneth como Fraser partilham dessa visão, ancorando a construção das relações jurídicas na intersubjetividade mobilizada na comunicação. Ambos assumem a visão de que o "que associa os parceiros do direito é, em última instância, o laço lingüístico que mantém a coesão de qualquer comunidade comunicacional" (HABERMAS, 1997, v. 2, p. 31).

Apesar desse eixo comum, o uso que Honneth e Fraser fazem da noção de direitos é distinto. Nota-se que Honneth (2003a) os concebe como expectativas morais recíprocas (instituídas ou não), ao passo que Fraser busca trabalhar com uma acepção mais institucionalizada de direito. $\mathrm{O}$ próprio Habermas já assinalava que se fala em di- 
reitos tanto do ponto de vista moral como do jurídico (HABERMAS, 1997, v. 1, p. 110). Na acepção habermasiana, o direito está diretamente ligado à moral, e ambos participam dos processos de integração social. Apesar dessa complementaridade, Habermas faz questão de distingui-los. "Em primeiro lugar, o direito não leva em conta a capacidade dos destinatários em ligar a sua vontade, contando apenas com sua arbitrariedade. Além disso, o direito abstrai da complexidade dos planos de ação a nível do mundo da vida, limitando-se à relação externa da atuação interativa e recíproca de determinados agentes sociais típicos. Finalmente, o direito não considera, conforme vimos, o tipo de motivação, contentando-se em enfocar o agir sob o ponto de vista de sua conformidade à regra" (idem, p. 147).

Além dessas diferenças, Habermas ressalta que a formação da moral está limitada à comunicação que se processa no mundo da vida, ao passo que o direito se constitui como um subsistema social que, ancorando-se nas práticas comunicativas ordinárias, precisa traduzi-las em linguagens específicas passíveis de regular e integrar outros sistemas. Para Habermas, o direito atua como meio de transformação do poder comunicativo em poder administrativo. Ele funciona como um elemento intermediário entre mundo da vida e sistemas, possibilitando a existência de trânsitos entre a linguagem ordinária e a formal.

A necessidade de converter-se em poder administrativo evidencia que o direito não pode ser pensado como algo tão abstrato como a moral. "O direito não regula contextos interacionais em geral, como é o caso da moral; mas serve como medium para a auto-organização de comunidades jurídicas que se afirmam, num ambiente social, sob determinadas condições históricas" (idem, p. 191).

Isso quer dizer que, para Habermas, o direito não pode ver-se inteiramente despido da ética. A ordem jurídica, em Habermas, "expressa os ideais de uma cultura política que propaga determinados valores e difunde concepções de bem" (MATTOS, 2006, p. 139). Ele concorda que o direito deve ser neutro, mas "se a neutralidade incluísse também a exclusão de questões éticas do discurso político em geral, este perderia sua força em termos de transformação racional de enfoques pré-políticos, de interpretações de necessidades e de orientações valorativas" (HABERMAS, 1997, v. 2, p. 35). De acordo com ele, a neutralidade adviria do argumentar; do ato de tornar-se compreensível ao outro. "É o procedimento que possui um caráter moral, portanto, universal" (MATTOS, 2006, p. 138). Ao regular uma comunidade concreta, discursos jurídicos devem abrirse não apenas para o uso moral da razão prática, mas também para sua utilização pragmática e ético-política.

Interessa-nos frisar aqui, exatamente, a importância desse uso ético. Segundo Habermas, os discursos ético-políticos são expressões de autoentendimento, conduzindo à definição de projetos identitários específicos. Isso implica que "toda ordem jurídica é também expressão de uma forma de vida em particular, e não apenas o espelhamento do teor universal dos direitos fundamentais" (HABERMAS, 2002, p. 253). A justiça, instituída no direito, não se rege por uma moral completamente isenta de valores, mesmo porque até as normas morais incorporam valores, desde que sejam generalizáveis (HABERMAS, 1997, v. 1, p. 193). Para Habermas, a teoria dos direitos não proíbe que os cidadãos validem uma concepção de bem. O que ela proíbe é "que se privilegie uma forma de vida em detrimento de outra" (HABERMAS, 2002, p. 256).

Esses apontamentos atravessam o debate em torno da definição do reconhecimento. Se Honneth parece mais fiel à proposta de Habermas ao defender uma justiça perpassada por concepções éticas, sua concepção de direito permanece bastante aquém da cuidadosa separação que Habermas delineia em relação à moral. Fraser, por outro lado, trata o direito como regras normatizadas com pretensão à fundamentação sistemática e universal, aproximando-se de Habermas. Ela, no entanto, esvazia sua concepção ao defender uma moral que se quer justa sem eleger definições sobre o bem viver. Aliás, ela defende um valor específico - a sociedade em que há paridade de participação -, mas insiste em dizer que tal definição é moldada apenas pelos parâmetros procedimentais da correção e não por uma concepção de bem.

\section{CONSIDERAÇÕES FINAIS}

O presente artigo buscou mapear o debate travado em torno da teoria do reconhecimento, apoiando-se, sobretudo, no diálogo entre Axel Honneth e Nancy Fraser. Procuramos demonstrar as categorias que norteiam os modelos de cada um deles, bem como as críticas reciprocamente 
endereçadas. Abordamos, ainda, a inscrição de tal debate no campo da teoria crítica, evidenciando a forte ligação (bem como os pontos de afastamento e crítica) dos dois autores com Jürgen Habermas.

Em nossa compreensão, um modelo analítico bastante rico para a análise de conflitos sociais e lutas emancipatórias pode emergir do atrito entre essas três perspectivas. A partir da junção de elementos indicados pelos três projetos de renovação da teoria crítica, pode-se compor um modelo complexo de justiça, mais apto a compreender as tramas relacionais por meio das quais a sociedade se repensa e se transforma. Esse modelo deve atentar, como o faz Honneth, para a importância das lutas intersubjetivas travadas quase que de forma subterrânea no cotidiano. É por meio delas que os sujeitos se auto-realizam e, por mais que a justiça não se resuma à auto-realização, não pode ser pensada sem ela. Como lembra Habermas, "uma teoria dos direitos entendida de maneira correta vem exigir exatamente a política do reconhecimento que preserva a integridade do indivíduo, até nos contextos vitais que conformam sua identidade" (HABERMAS, 2002, p. 243).

Mas o modelo também deve explicitar, seguindo Fraser e Habermas, a importância de lutas coletivas travadas argumentativamente em uma esfera pública que permite a alteração de padrões interacionais instituídos e a revisão de regras informais de convivência. A participação paritária em tal esfera é fundamental, pois somente por meio dela a sociedade pode se reconstruir reflexivamente. Ainda que outras práticas comunicativas sejam importantes para as lutas sociais, como deixa a entender Honneth, a livre troca de razões tem um papel não negligenciável que possibilita a formalização do direito e sua ligação com a moral. Moral essa que não pode ser pensada como desencarnada de concepções sobre o bem viver. O que é necessário é que as concepções éticas encarnadas no direito não sejam sectáticas ou repressivas, o que só pode ser alcançado por meio de uma livre e irrestrita deliberação entre os membros de uma sociedade de jurisconsortes. Delibe- ração essa em que se fazem presentes argumentos pragmáticos, éticos e morais, como aponta Habermas.

Outro aspecto central a esse modelo seria a atenção sistemática às desigualdades materiais, que não podem permanecer como pano de fundo. Como lembra Zurn, a agenda da teoria crítica parece, em vários momentos, mais pautada pela relevância filosófica das questões do que pela promoção de relações mais justas: "uma teoria que mantém a esperança de um retorno da justiça econômica para o primeiro plano da teoria crítica promete uma volta a questões tradicionais adiadas por muito tempo" (ZURN, 2005, p. 90). Mesmo que a economia não possa ser pensada de forma absolutamente desligada de valores, ela possui uma certa autonomia, como indica Fraser. A justiça social deve incluir uma atenção permanente a essa dimensão, fazendo-se necessário pensar formas de associação dela com os conflitos morais em torno de padrões simbólicos. Esse esforço é, justamente, a maior contribuição de Fraser, como bem assinala Zurn (2003). Seu dualismo perspectivo é bastante enriquecedor, desde que permaneça aberto à incorporação de outras dimensões da justiça.

Ainda que não possamos desenvolver, neste artigo, o modelo aqui esboçado, nossa intenção é evidenciar que as perspectivas de Honneth e Fraser podem ser combinadas em um viés, simultaneamente, atento à auto-realização de sujeitos e à participação paritária deles em interações sociais. Afinal, se é só por meio da participação interativa que a auto-realização pode ser pensada de maneira moral, é apenas através de uma socialização minimamente saudável que os indivíduos podem afirmar-se como sujeitos e participar (HABERMAS, 1997, v. 1, p. 111). Com base nesses dois pilares, pode-se conceber uma sociedade que se constrói justa, por meio da troca livre e permanente de pretensões de validade criticáveis. Um tal modelo combinado poderia arejar a teoria crítica, reagrupando ética e moral, cultura e economia, lutas invisíveis e lutas públicas, Honneth e Fraser.

Ricardo Fabrino Mendonça (ricardofabrino@hotmail.com) é doutorando pelo Programa de Pós-Graduação em Comunicação Social da Universidade Federal de Minas Gerais (UFMG), bolsista da Fundação de Amparo à Pesquisa do Estado de Minas Gerais (Fapemig) e pesquisador do Grupo de Pesquisa em Mídia e Espaço Público (EME). 


\section{REFERÊNCIAS BIBLIOGRÁFICAS}

ADORNO, T. W. \& HORKHEIMER, M. 1985. Dialética do esclarecimento. Rio de Janeiro : J. Zahar.

ASSIS, M. P. F. 2006. Deliberação, diferença e reconhecimento : da esfera pública "neutra" à participação paritária. Trabalho apresentado no I Congresso Anual da Associação Brasileira de Pesquisadores de Comunicação e Política, realizado em Salvador.

BERNARDINO, J. 2002. Affirmative Action and the Re-Discussion of the Brazilian Racial Democracy Myth. Estudos Afro-Asiáticos, Rio de Janeiro, v. 24, n. 2, p. 247-273.

COSTA, S. 2002. A construção sociológica da raça no Brasil. Estudos Afro-Asiáticos, Rio de Janeiro, v. 24, n. 1, p. 35-62.

CRUZ, M. M. 2007. Vozes das favelas na internet : lutas discursivas por estima social. Belo Horizonte. Dissertação (Mestrado em Comunicação Social). Universidade Federal de Minas Gerais.

EMCKE, C. 2000. Between Choice and Coercion : Identities, Injuries, and Different Forms of Recognition. Constellations, Oxford, v. 7, n. 4, p. 483-495, Dec.

FERES JÚNIOR, J. 2006. Semantic Elements of Racial Discrimination in Brazil : Going beyond the Sociology of Modernity. Revista Brasileira de Ciências Sociais, v. 21, n. 61, p. 163176.

FRASER, N. 1997 [1995]. From Distribution to Recognition? Dilemmas of Justice in a 'Postsocialist' Age. In : Justice Interruptus : Critical Reflections on the 'Postsocialist' Condition. London : Routledge.

1999. Rethinking the Public Sphere : a Contribution to the Critique of Actually Existing Democracy. In : DURING, S. (ed.). The Cultural Studies Reader. Londres : Routledge.

2000. Rethinking Recognition. New Left Review, London, n. 3, p. 107-120, May-June.

2001. Recognition without Ethics? Theory, Culture \& Society, London, v. 18, n. 2-3, p. 21-42, June.

2003a. Social Justice in the Age of Identity
Politics : Redistribution, Recognition, and Participation. In : FRASER, N. \& HONNETH, A. Redistribution or Recognition : a PoliticalPhilosophical Exchange. London : Verso.

2003b. Distorted beyond All Recognition : a Rejoinder to Axel Honneth. In : FRASER, N. \& HONNETH, A. Redistribution or Recognition : a Political-Philosophical Exchange. London : Verso.

HABERMAS, J. 1980a. Técnica e ciência como "ideologia". In : BENJAMIN, W. (org.). Textos escolhidos. São Paulo : Abril Cultural.

1980b. O conceito de poder em Hannah Arendt. In : FREITAF, B. \& ROUANET, S. P. (orgs.). Habermas. São Paulo : Ática.

1983. The Theory of Communicative Action. V. 1 : Reason and the Rationalization of Society. Boston : Beacon.

1984. Mudança estrutural da esfera pública. Rio de Janeiro : Tempo Brasileiro.

1987. The Theory of Communicative Action. V. 2. Boston : Beacon.

1992. Further Reflections on the Public Sphere. In : CALHOUN, C. (ed.). Habermas and the Public Sphere. Cambridge, Mass. : MIT.

1990. Ações, atos de fala, interações mediadas pela linguagem e mundo da vida. In : . Pensamento pós-metafísico. Rio de Janeiro : Tempo Brasileiro.

1994. Struggles for Recognition in the Democratic Constitutional State. In GUTMANN, A. (ed.). Multiculturalism : Examining the Politics of Recognition. Princeton : Princeton University.

1995. Três modelos normativos de democracia. Lua Nova, São Paulo, n. 36, p. 39-53.

1997a. Direito e Democracia : entre a facticidade e a validade. V. 1. Rio de Janeiro : Tempo Brasileiro.

1997b. Direito e Democracia : entre a facticidade e a validade. V. 2. Rio de Janeiro : Tempo Brasileiro.

2002. A inclusão do Outro: estudos de teoria política. São Paulo : Loyola. 
HONNETH, A. 2001. Recognition or Redistribution? Changing Perspectives on the Moral Order of Society. Theory, Culture \& Society, London, v. 18, n. 2-3, p. 43-55, June.

2003a [1992]. Luta por reconhecimento : a gramática moral dos conflitos sociais. São Paulo : ed. 34.

2003b. Redistribution as Recognition : a Response to Nancy Fraser. In : FRASER, N. \& HONNETH, A. Redistribution or Recognition : a Political-Philosophical Exchange. London : Verso.

2003c. The Point of Recognition : a Rejoinder to the Rejoinder. In : FRASER, N. \& HONNETH, A. Redistribution or Recognition : a Political-Philosophical Exchange. London : Verso.

LOPES, J. R. L. 2000. Human Rights and Egalitarian Treatment : Issues of Impunity, Dignity and Liberty. Revista Brasileira de Ciências Sociais, São Paulo, v. 15, n. 42, p. $77-$ 100.

MARQUES, A. C. S. 2003. Da esfera cultural à esfera política : a representação de grupos de sexualidade estigmatizada nas telenovelas e a busca por reconhecimento. Belo Horizonte. Dissertação (Mestrado em Comunicação Social). Universidade Federal de Minas Gerais.

MARKELL, P. 2000. The Recognition of Politics : a Comment on Emcke and Tully. Constellations, Oxford, v. 7, n. 4, p. 496-506, Dec.

MATTOS, P. 2004. Recognition, between Justice and Identity. Lua Nova, São Paulo, n. 63, p. 143-160.

2006. Sociologia política do reconhecimento. São Paulo : Annablume.

MCBRIDE, C. 2005. Deliberative Democracy and the Politics of Recognition. Political Studies, Oxford, v. 53, n. 3, p. 497-515, Oct.

MEAD, G. H. 1993. Espiritu, persona y sociedad. Ciudad de México : Paidós.
MENDONÇA, R. F. \& MAIA, R. 2006. Exclusão e deliberação : buscando ultrapassar as assimetrias do intercâmbio público de razões. Contracampo, Rio de Janeiro, n. 15, p. 201218, jul.-dez.

NEVES, P. S. C. 2005. Political Action between Recognition and Redistribution : Anti-Racist Engagement Dilemmas in Brazil. Revista Brasileira de Ciências Sociais, São Paulo, v. 20, n. 59, p. 81-96.

NOBRE, M. 2003. Apresentação : luta por reconhecimento : Axel Honneth e a teoria crítica. In : HONNETH, A. Luta por reconhecimento. São Paulo : ed. 34.

SOUZA, J. 2000a. Charles Taylor e a teoria crítica do reconhecimento. In : SOUZA, J. (org.) A modernização seletiva : uma reinterpretação do dilema brasileiro. Brasília : UNB.

2000b. Uma teoria crítica do reconhecimento. Lua Nova, São Paulo, n. 50, p. 133158 .

2003. A construção social da subcidadania. Para uma Sociologia Política da modernidade periférica. Belo Horizonte : UFMG.

(org.). 2006. A invisibilidade da democracia brasileira. Belo Horizonte : UFMG.

TAYLOR, C. 1994 [1992]. The Politics of Recognition. In : GUTMANN, A. (ed.). Multiculturalism : Examining the Politics of Recognition. Princeton : Princeton University.

1997. As fontes do self. São Paulo : Loyola.

TULLY, J. 2000. Struggles over Recognition and Distribution. Constellations, Oxford, v. 7, n. 4, p. 469-482, Dec.

ZURN, C. F. 2003. Identity or Status? Struggles over Recognition in Fraser, Honneth, and Taylor. Constellations, Oxford, v. 10, n. 4, p. 519-537, Dec.

2005. Recognition, Redistribution, and Democracy : Dilemmas of Honneth's Critical Social Theory. European Journal of Philosophy, Oxford, v. 13, n. 1, p. 89-126, Apr. 


\section{RECOGNITION IN DEBATE: HONNETH'S AND FRASER'S MODELS AND THEIR RELATIONSHIP TO THE HABERMASIAN LEGACY}

\section{Ricardo Fabrino Mendonça}

This article presents a sketch of the debate between Axel Honneth and Nancy Fraser over the notion of recognition, seeking specifically to understand some of the aspects that run through the Habermasian project of critical theory. If at a first glimpse, Honneth's proposal (a theory of justice based on the notion of self-fulfillment) and that of Fraser (based on the principle of parity of participation) appear to be unreconcilable, some common elements can be identified when we keep the background in which these theories operate in mind. We believe that the possible production of a model of recognition that is capable of combining Fraser's and Honneth's proposals depends upon making explicit some of the Habermasian premises that remain implicit within the perspectives we are analyzing here. This article sketches out comparisons and approximations between the three authors with particular regard to three aspects: the importance of ordinary interaction, the material dimension of social struggles and the relationships between law and morality.

KEYWORDS: recognition; critical theory; Honneth; Fraser; Habermas. 


\section{RECONNAISSANCE EN DEBAT: LES MODELES DE HONNETH ET FRASER DANS LEUR RAPPORT AVEC LE LEGS HABERMASIEN}

\section{Ricardo Fabrino Mendonça}

Cet article cherche à tracer le débat entre Axel Honneth et Nancy Fraser autour de la notion de reconnaissance, et essaye de comprendre certains des aspects qui passent au travers du projet habermasien de la théorie critique. Si la proposition de Honneth (d'une théorie de la justice appuyée sur la notion d'autoréalisation) et celle de Fraser (fondée sur le principe de la parité de la participation) semblent, de prime abord, inconciliables, certains éléments comuns sont identifiés lorsqu'on prend en compte le fond sur lequel ils travaillent. Nous croyons que la production éventuelle d'un modèle de reconnaissance associant les propositions de Fraser et Honneth dépend de l'explicitation de quelques postulats habermasiens qui sont implicites aux perspectives de notre analyse. Le présent article fait des comparaisons et des rapprochements entre les trois auteurs en ce qui concerne trois aspects: l'importance des interactions ordinaires, la dimension matérielle des luttes sociales et les rapports entre le droit et la morale.

MOTS-CLÉS: reconnaissance; théorie critique; Honneth; Fraser; Habermas. 